\title{
Sensory evaluation of polyphenol-rich millet-based muffins and their effect on in vitro starch digestion
}

\author{
A. Almaski, S. Coe, H. Lightowler and S. Thondre \\ Functional Food Centre, Department of Sport and Health Sciences, Oxford Brookes University, Gipsy Lane, \\ Headington, Oxford OX3 OBP
}

Millet is a functional grain that has attracted interest for many years and has a unique position among other cereals due to its high content of polyphenols, antioxidants and dietary fibre ${ }^{(1)}$. It has been found that the digestion, absorption and metabolism of both starch and sucrose can be affected by polyphenols and their metabolites ${ }^{(2)}$. Furthermore, polyphenols have been shown to reduce the sugar release from foods that are rich in carbohydrates ${ }^{(3)}$.

Sensory analysis of new products plays a significant role in food choices. The increasing demand for new and healthy bakery products has resulted in a new market for alternative ingredients. The addition of millet grain to existing baked products is a simple and appropriate way of enhancing their nutritional value to provide health benefits ${ }^{(4)}$.

The aim of this study was to evaluate the effect of polyphenol-rich millet-based muffins on in vitro starch digestion and to conduct a sensory principles test to assess their overall acceptance.

Laboratory studies were conducted to determine the in vitro starch digestion of selected millet-based muffins and analyse reducing sugar using the 3,5-Dinitrosalicylic acid (DNS) colorimetric method ${ }^{(3)}$. Descriptive sensory evaluation of millet-based muffins was conducted in 30 healthy volunteers (19 female and 11 male) by scoring different attributes using a 9-point hedonic scale.

Table 1. Rapidly digestible starch (RDS) and slowly digestible starch (SDS) in control muffins and different types and forms of millet-based muffins

\begin{tabular}{llc}
\hline Samples & $\begin{array}{c}\text { RDS } \\
\text { (mg/g sample) } \\
\text { Mean }\end{array}$ & $\begin{array}{c}\text { SDS } \\
\text { (mg/g sample) } \\
\text { Mean }\end{array}$ \\
\hline Control & $84 \cdot 7$ & $69 \cdot 1$ \\
Finger millet flour & $30 \cdot 6$ & $23 \cdot 7$ \\
Finge millet grain & $16 \cdot 6^{*}$ & $27.9^{*}$ \\
Koda millet grain & $11^{*}$ & $39 \cdot 6^{*}$ \\
\hline
\end{tabular}

* Significance level $\mathrm{p}<0.05$.

RDS = sugar released after 20 min of digestion

SDS $=$ sugar released between 20 and $120 \mathrm{~min}$ of digestion.

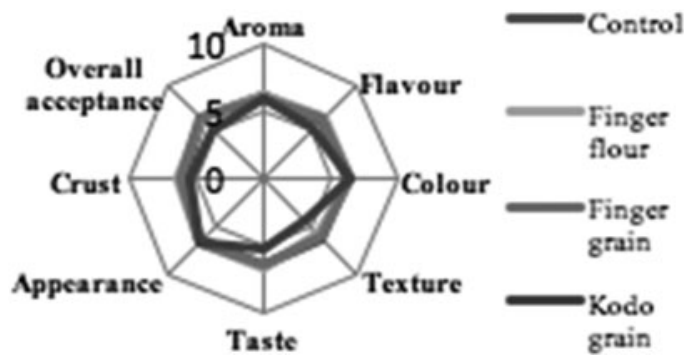

Fig. 1. Spider graph showing sensory analysis data for millet based

These results show that there was a reduction in sugar release in all three millet-based muffins compared to a wheat based muffin (control) (Table 1). The control muffin and finger millet flour-based muffins showed a significantly higher rapidly digested starch (RDS) compared to the grain-based muffins (finger millet and kodo millet; $p<0.05$ ). Figure 1 shows that the control muffin and muffins made with finger millet flour and grain were significantly more acceptable compared to muffins made with kodo millet grain. The overall acceptance was significantly different $(\mathrm{p}=0.005)$ between kodo millet grain-based muffins and finger millet-based muffins in both forms. The results of this study provides valuable data for using millet in baked products which can result in increased utilization of millet and production of nutritious baked products to consume as part of the daily diet.

1. Amadou I, Gounga M \& Le G (2013) Emir J Food Agric 25, 501-508.

2. Hithamani G \& Srinivasan K (2014) Food Chem 164, 55-62.

3. Coe S, Fraser A \& Ryan L (2013) Int J Food Sci 6.

4. Lizia S \& John S (2014) IJSR 3, 2319-7064. 